\title{
Performance Evaluation of an Induction Machine with Auxiliary Winding for Wind Turbine Power
}

\author{
Riadh W. Y. Habash, ${ }^{1}$ Qianjun Tang, ${ }^{1,2}$ Pierre Guillemette, ${ }^{2}$ and Nazish Irfan ${ }^{1}$ \\ ${ }^{1}$ School of Electrical Engineering and Computer Science, University of Ottawa, Ottawa, ON, Canada K1N 6N5 \\ ${ }^{2}$ Trias Innovations Group, Ottawa, ON, Canada K1L $8 \mathrm{~K} 4$ \\ Correspondence should be addressed to Riadh W. Y. Habash, rhabash@site.uottawa.ca
}

Received 27 April 2012; Accepted 9 August 2012

Academic Editors: O. O. Fasina and K. T. Lee

Copyright (C) 2012 Riadh W. Y. Habash et al. This is an open access article distributed under the Creative Commons Attribution License, which permits unrestricted use, distribution, and reproduction in any medium, provided the original work is properly cited.

\begin{abstract}
The purpose of this paper is to reinforce with theoretical and experimental evaluation the effectiveness of employing an induction generator to enhance the performance of a small wind energy converter (SWEC). With this generator, the SWEC works more efficiently and therefore can produce more energy in a unit turbine area. To verify the SWEC performance, a model has been proposed, simulated, built, and experimentally tested over a range of operating conditions. The results demonstrate a significant increase in output power with an induction generator that employs an auxiliary winding, which is only magnetically coupled to the stator main winding. It is also shown that the operating performance of the induction machine with the novel proposed technique is significantly enhanced in terms of suppressed signal distortion and harmonics, severity of resistive losses and overheating, power factor, and preventing high inrush current at starting.
\end{abstract}

\section{Introduction}

Wind energy has been shown to be one of the most feasible sources of renewable energy. It presents attractive opportunities to a wide range of people, including investors, entrepreneurs, and users. Wind along with other renewable energy sources such as bio and hydro require electromechanical systems to convert naturally available energy sources to rotation through prime movers and then to electricity through electric generators. The prime movers and generators are critical components of such systems that must be affordable, reliable, environmentally safe, and user-friendly.

Self-excited induction generators (SEIG) (squirrel cage and/or wound rotor) are strong candidate for such applications. The fact that they are not yet widely used in the field reflects a major gap in knowledge. An attractive option is to take an "off-the-shelve" induction machine and modify it suitably to provide optimized performance in terms of efficiency, suppressed signal distortion and harmonics, resistive losses and overheating, and power factor.

In the 1935s, Bassett and Potter [1] demonstrated the possibility of using an induction machine, in the self-excited mode. Since then, the use of induction machines as generators is becoming more popular for the renewable sources [2-5]. The simplicity and flexibility exhibited by the induction machine in providing electromechanical energy conversion make it the favoured choice for wind systems operating with an existing utility grid. Induction generators in general have many advantages: simple, cheap, reliable, brushless (squirrel cage rotor), no synchronizing equipment, absence of DC power supply for excitation, good overspeed capability, inherent protection against short circuit, easy to control, not producing sparks like DC motors, and require very little maintenance [6-8]. The induction machine, however, is not without its drawbacks including the need for a high starting current, reactive power for operation, and poor voltage regulation under varying speeds. Thus its power factor is inherently poor, and it is worse especially at starting and when running with light loads or when operating with power electronics converters. At starting, the input power to an induction motor is mainly reactive. It draws up to 6 times of its rated current at about 0.2 power factor and takes some time to come to its rated speed, where the power factor improves significantly 
to above 0.6 depending on the load. This high starting current at a poor power factor usually affects the loads and limits the application range of the machine; accordingly, new techniques should be developed to enhance its performance.

In the literature, several techniques to improve the power factor and accordingly the performance of induction machines have been suggested, including the synchronous compensation, fixed capacitors, fixed capacitors with switched inductor, solid-state power factor controller, and switched capacitors [9-13]. A three-phase induction motor equipped with a three-phase auxiliary winding in delta configuration, which is magnetically coupled to the main winding connected in a star configuration, has recently been proposed as well [9-11]. This scheme uses thyristor switched capacitors connected in parallel to each phase of the auxiliary winding. A three-phase asynchronous machine which employs an auxiliary three-phase winding in wye configuration together with a pulse width modulation (PWM) inverter to supply the excitation to the machine has also been suggested [9-11, 13]. However, these techniques suffer several drawbacks. The synchronous compensation technique is complex and not cost effective. Other techniques incorporate directly the connection of capacitor and lead to the problems of voltage regeneration and over voltages and a very high current inrush during starting. In addition, techniques incorporating controlled switches in the stator winding circuit generate large harmonic current in the machine and in the line.

In this paper, an enhanced squirrel cage induction generator (SCIG) model with an auxiliary winding is proposed, analyzed, and verified experimentally. A simple and low-cost scheme where resonance can be achieved without connection to the terminals is proposed. This may be achieved by using an LC resonant circuit as an auxiliary winding which is only magnetically coupled to the stator main winding to supply leading reactive power to the machine. Due to its high improved characteristics, this generator can enhance the performance of the SWEC.

\section{Induction Generator for Wind Power}

An induction machine operates as a generator if a supply of reactive power is available to provide the machine's excitation. A SEIG, although known for more than a half century, is still a subject of considerable attention. The interest in this topic is primarily due to the application of SEIG in isolated power systems. When an induction machine is driven at a speed greater than the synchronous speed (negative slip) by means of an external prime mover, the direction of induced torque is reversed and theoretically it starts working as an induction generator [14]. Self-excitation in an induction machine occurs when the rotor is driven by a prime mover and a suitable capacitance is connected across the stator terminals, allowing the induction machine to be used as a standalone generator [15]. An induction generator does not develop reactive power but it consumes it, so it is required to connect a capacitor with the auxiliary winding for selfexcitation. This capacitor develops the required reactive power needed by both generator and load, and any reactive power diverted to the load causes a major drop in the generator voltage. Nonetheless, because of its inherently poor voltage regulation and efficiency, the single-phase induction generator has had few applications in a wind generation. One attempt at addressing the voltage regulation weakness is a self-regulated self-excited single-phase induction generator which uses two capacitors connected in shunt and in series with the main and the auxiliary winding of the machine, respectively $[16,17]$. On the other hand, incorporation of copper for the rotor bars and end rings in place of aluminum would result in improvements in motor energy efficiency $[18,19]$.

The induction generator can work in two modes (e.g., grid connected and isolated mode). In case of a gridconnected mode, the induction generator can draw reactive power either from the grid but it will place a burden on the grid or by connecting a capacitor bank across the generator terminals [20].

The main factor which characterizes the induction machine is its power curve. The shaft power from the electric generator is calculated using loss separation as follows:

$$
P_{\text {shaft }}=P_{\text {output }}+P_{\text {ohmic }}+P_{\text {core }}+P_{\text {friction }} .
$$

The output power $\left(P_{\text {output }}\right)$ is measured using a power analyser. The analyser determines the power, electrical frequency, and stator currents from the generator to a variable resistive load bank. The load bank is used to vary the load on the generator, at a particular incident wind speed, in order to determine the maximum power point. The shaft power $\left(P_{\text {shaft }}\right)$ is then determined by incorporating resistive losses $\left(P_{\text {ohmic }}\right)$ associated with power loss in the stator resistance, core loss $\left(P_{\text {core }}\right)$ associated with hysteresis and eddy-current losses in the iron core of the machine, and friction and windage losses in the generator $\left(P_{\text {friction }}\right)$.

The emergence of new grid codes will pose wind turbine developers to new challenges, mainly with a high penetration of wind power in the network, the wind turbines should be able to continuously supply the network during voltage sags. These new grid codes which are being proposed in Norway [21] and other countries will most likely influence the topology of the electrical system (generator and network interface) of future wind turbines. To cope with these new challenges, several industries have already directed research efforts to the development of machines through capability. Among the technology choices, SCIGs are a very attractive for wind power generation because they are robust, inexpensive, and have low cost and maintenance requirement.

Since the SCIG draws reactive power from the grid, this concept was extended with a capacitor bank for reactive power compensation. Smoother grid connection was also achieved by incorporating a soft starter. Because the generator operation is only stable in the narrow range around the synchronous speed, the wind turbine equipped with this type of generator is often called fixed-speed system. The grid connection scheme of a fixed speed wind turbine with SCIG is shown in Figure 1.

The need for reactive power support and poor power factor are the two major drawbacks of induction generators. 


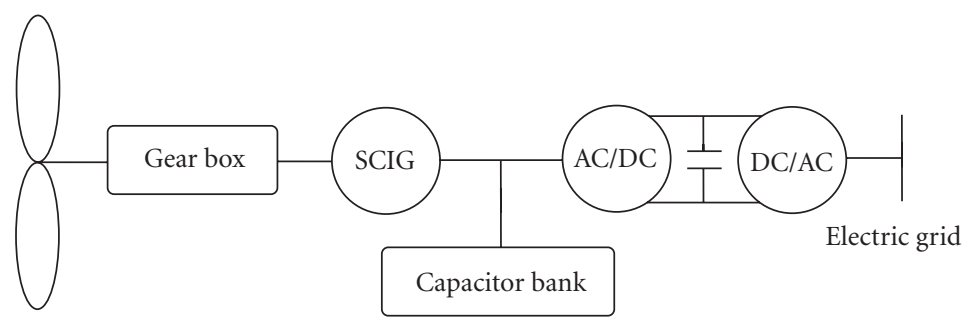

Figure 1: Grid connection scheme for a wind turbine.

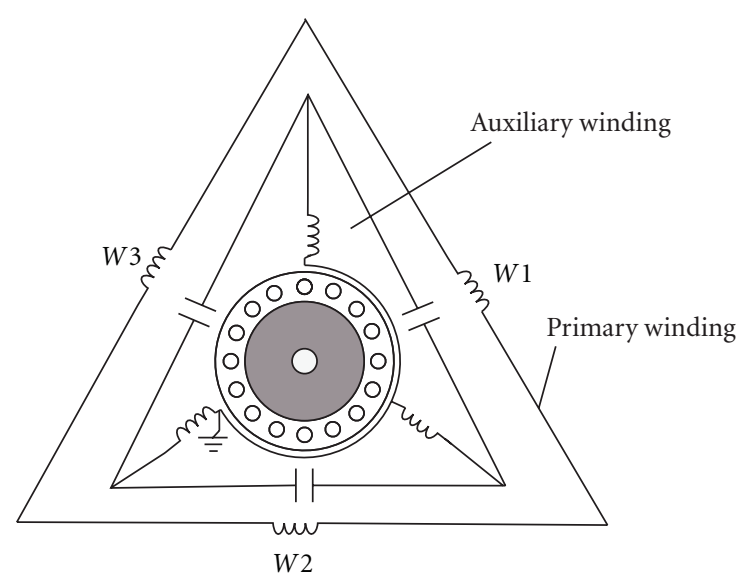

FIgURE 2: A three-phase generator with auxiliary winding.

Induction generators as well as the load, which are generally inductive in nature, require the supply of reactive power. Unbalanced reactive power operation results in voltage variation. Reactive power control by using VAR compensator (SVC) [22], or static-synchronous compensator (STATCOM) [23], work well but they may add harmonics to the electrical network while compensating reactive power continuously and may not be able to provide the adequate amount of reactive power under varying input and/or load conditions such as wind energy sources which fluctuate highly in nature. On the other hand, several techniques to improve the power factor of induction machines have been suggested, namely, capacitors, capacitors with switched inductor, and solid-state power factor controllers $[10,11]$. The initiation of the induction machine excitation can be viewed as the response of a resonant circuit, comprising the machine and the capacitance connected to its terminals. Once resonance is approached, the generated voltage will grow [24].

\section{Proposed Technique}

In this paper, a passive technique is proposed to overcome most of the drawbacks noted above. The proposed technique makes use of an auxiliary winding connected in wye configuration (with capacitors) as shown in Figure 2. It is only magnetically coupled to the main winding. Therefore, the performance can be increased without any additional active mass. This method uses combined (two three-phase) windings on the stator similar to the scheme used in deltastar connected three-phase transformer (neglecting the rotor effect). The main stator winding is the primary connected in delta to the source and the auxiliary winding is the secondary in wye. It means that the third harmonics component would be short circuited by the delta side with the result that there will be no third harmonic voltage across the lines. In addition, the above two sets of windings have the same poles, so they share the same operating frequency. Basing on delta-wye transformation of the auxiliary windings and on transformer approach of the induction machine, the electric model per phase of the proposed strategy is shown in Figure 3. In the proposed scheme, a three phase induction machine with a dual stator winding is employed. One set of the three phase windings (main) is directly connected to the supply while the other set of the three phase windings (auxiliary) is connected to a capacitor. Both windings (main and auxiliary) are magnetically coupled but electrically isolated. The main idea of the proposed scheme is to connect suitable capacitor in auxiliary windings such that the main winding will carry mainly active power while the auxiliary winding will carry mainly reactive power.

The couplings between the elements of the machine are presented as ideal transformers with $N_{a}$ : the turn's ratio between auxiliary winding and stator $\left(N_{a}\right.$ less than 1$) ; N_{r}$ : the turn's ratio between rotor and stator $\left(N_{r}\right.$ less than 1$)$; $N_{r a}$ : the turn's ratio between rotor and auxiliary winding $\left(N_{r a}\right.$ less than 1). Because of no electric connection between the two sets of windings and the usage of the properly designed windings, the electromagnetic compatibility (EMC) of the machine is improved significantly.

With sufficient ampere-turn capability of the auxiliary winding, it is possible to obtain nearly unity power factor operation at the terminals of the main winding over a range of load conditions including a rated load. The auxiliary winding gives priority to the harmonic suppression, and also has the function of a reactive compensation which provides the means for maximum energy conversion and efficiency.

The winding geometry of the modified generator (Trias) combines inductive and capacitive effects into the machine, thereby creating an effect comparable to a resistive load as shown in Figure 4. To compute the reactance needed for power correction of a typical induction machine, we need to estimate the negative reactance power and therefore the capacitance along the operating conditions of the machine. 


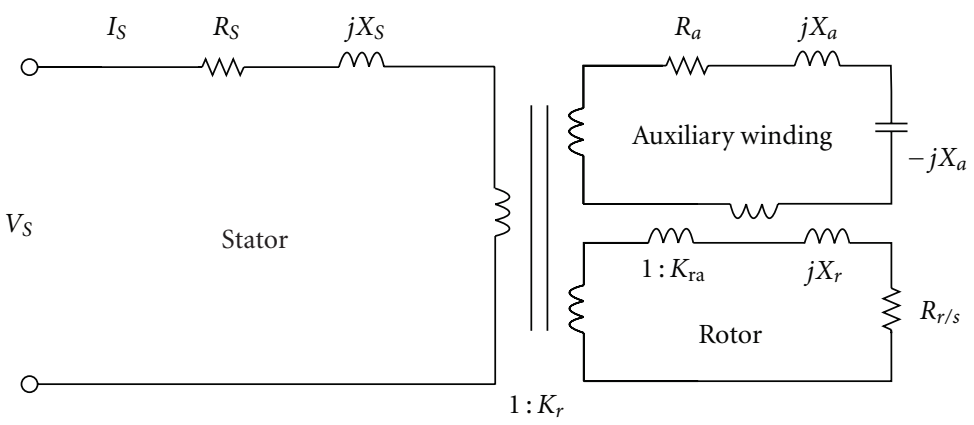

Figure 3: Model per phase of the proposed strategy.

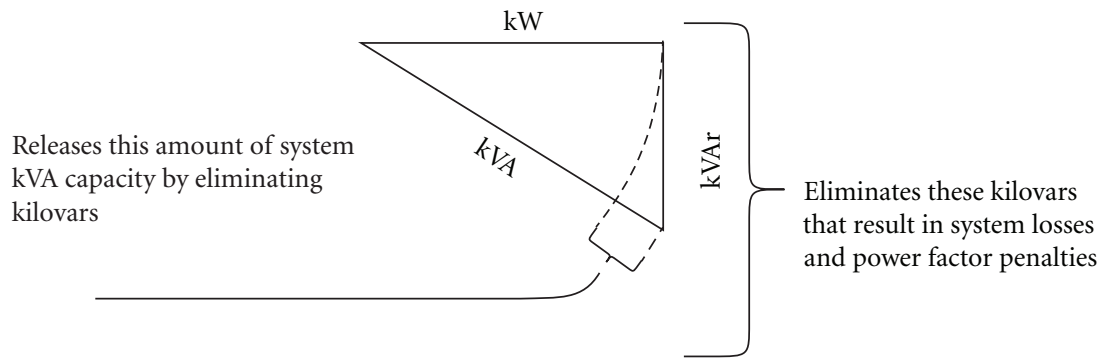

Figure 4: Power triangle of an induction machine.

It is important therefore to determine the capacitor value for a minimum and maximum compensation of the power factor and also to take into consideration the value of the current that flows in the auxiliary winding as the size of the wire depends strongly on it. Usually, the current in auxiliary winding is leading over the stator current but it is lower in magnitude compared to the stator current. This is a must situation during operation as the auxiliary winding has smaller wire size in order to be accommodated in the same slots with the main winding Consider.

$$
\begin{aligned}
& X_{\mathrm{ceq}}=\frac{|V|^{2}}{Q_{c}}, \\
& C=-\frac{1}{\omega X_{\mathrm{ceq}}},
\end{aligned}
$$

where $X_{\text {ceq }}$ is the reactive impedance, $V$ is the rms voltage across the load, $Q_{c}$ is the capacitive reactive power, and $\omega$ is the angular frequency. As an induction motor, all the energy supplied by the power utility goes into creating real work $(\mathrm{kW})$. In doing so, the machine will operate at near unity power factor, almost with all kinds of loads. Also, the machine has the same characteristic when operating as a generator.

Stable operating points for the SEIG under balanced conditions may be determined from a standard equivalent circuit by simply balancing the real- and reactive-power flow between the machine, the excitation capacitance, and load. One method for solving at these operating points has been presented in [25]. The amount of inductance and capacitance required to maintain the generated voltage at a rated value can therefore be determined for a range of operating conditions. To determine operating points when

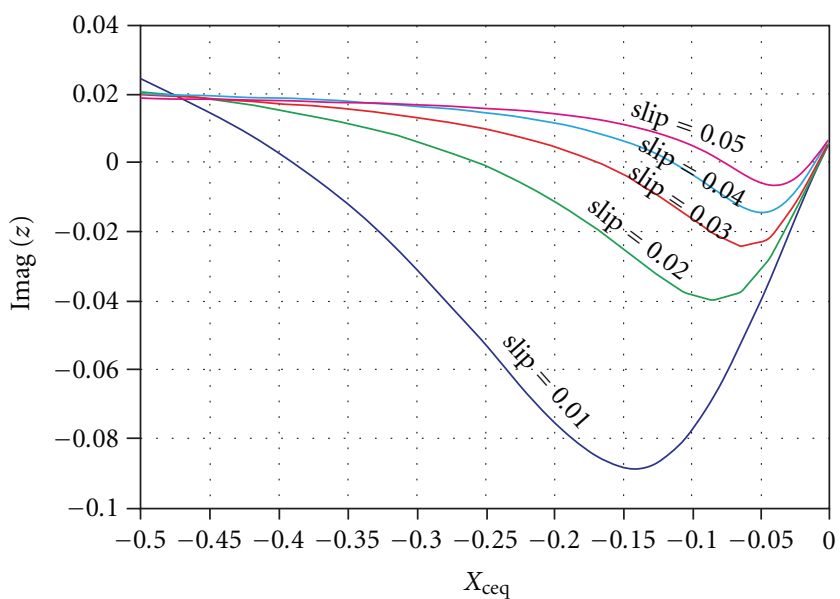

FIGURE 5: Imaginary part of the total impedance $Z$ as a function of $X_{\text {ceq }}$ for different values of the slip.

the loading on the generator is unbalanced, it is necessary to use generalised electric machine theory.

Since both the windings (main and auxiliary) occupy the same slots and are therefore mutually coupled by their leakage flux, they can be modeled by two branches each having separate leakage reactance and resistance with a common mutual inductance. The effect of capacitor in auxiliary winding is represented by $X_{\text {ceq. }}$. For a $920 \mathrm{hp}, 460 \mathrm{~V}, 6$ poles, and $60 \mathrm{~Hz}$ induction motor, Figure 5 shows the variation of imaginary part of the impedance $(Z)$ with respect to $X_{\text {ceq }}$ for different values of slip and also demonstrates that a unity power factor can be obtained at different values of the slip. It can be observed that for a particular slip, a unity power 


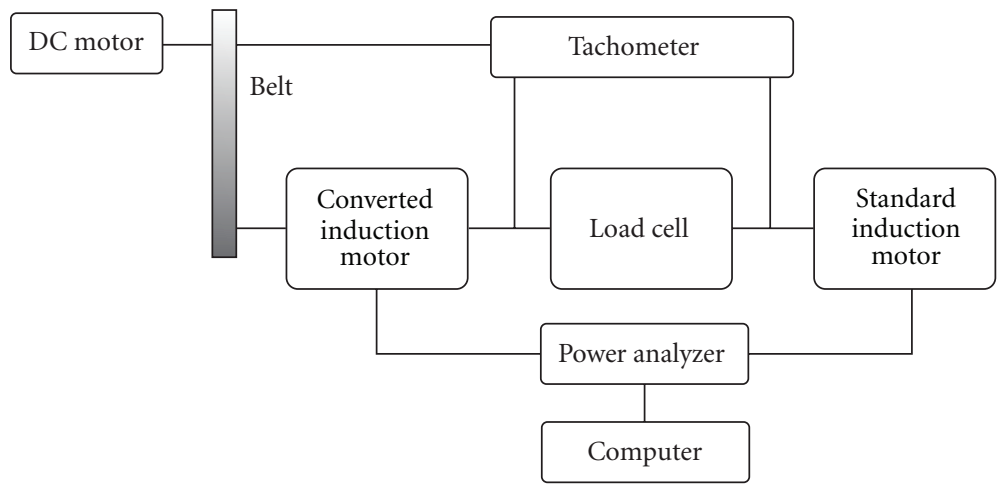

FIGURE 6: Typical measurement setup for an induction machine performance.

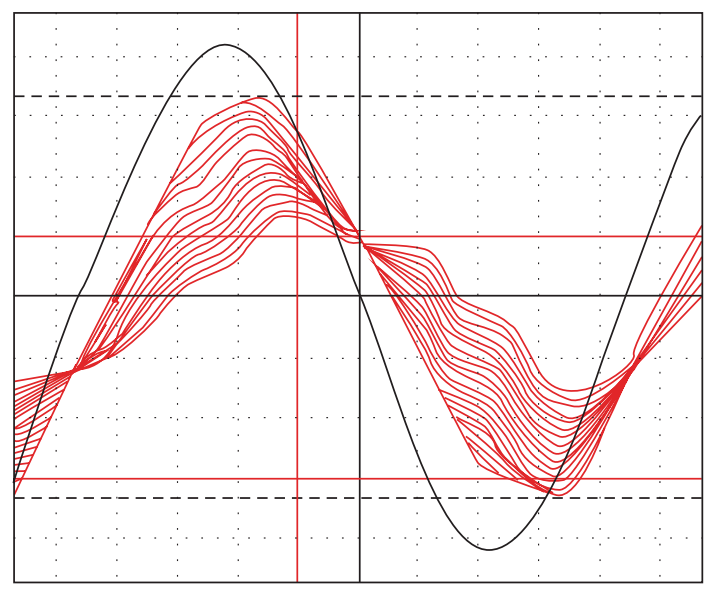

(a)

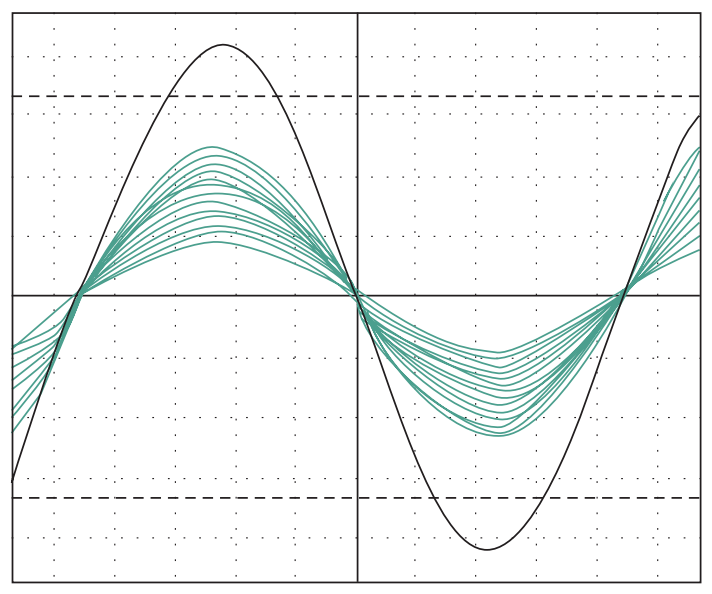

(b)

FIgURE 7: Signal acquired from an induction machine. (a) Standard. (b) With auxiliary winding.

factor can be obtained at two different values of $X_{\text {ceq. }}$. The larger value of $X_{\text {ceq }}$ (smaller capacitance) corresponds to a small value of current and a smaller value of $X_{\text {ceq }}$ (larger capacitance) corresponds to a higher current. It may also be concluded from Figure 5 that to obtain a unity power factor at higher load requires smaller value of $X_{\text {ceq }}$ than that required for lighter load.

\section{Experimental Results}

There exist several standards for testing electric machinery. For induction machines, the three most important ones are IEEE Standard 112, currently in use in USA and some parts of the world; JEC 37, in Japan; IEC 34-2, in use in most European countries. In Canada, the standard specified in the Energy Efficiency Regulations is "Method for Determining Energy Performance of Three-phase Induction Motors: CSA C390-98." This Standard is equivalent to the well-recognized standard "IEEE 112-1996, Method B: Test Procedure for Poly-phase Induction Motors and Generators."

A typical experimental test to compare a standard SCIG with the proposed one (standard SCIG with a passive auxiliary winding: Trias) is shown in Figure 6. A DC motor
TABLE 1: Experimental test results of a standard and trias induction machine.

\begin{tabular}{lcc}
\hline Quantity & Standard & Trias \\
\hline Voltage (V) & 117 & 117 \\
Current (A) & 2.69 & 0.426 \\
Power (W) & 43.2 & 43.7 \\
Power factor & -0.130 & -0.870 \\
Reactive power (VAR) & -311 & -24.1 \\
\hline
\end{tabular}

is connected to the shaft of the two induction machines as a drive. By varying the load from $10 \%$ up to $125 \%$ of the full load, different values of input power, power factor, reactive power, and apparent power are, respectively, obtained. The experimental results recorded during the experimental tests are given in Table 1 and Figures 7 and 8. It is shown that the induction machine with auxiliary winding (Trias) provides higher operating performance in terms of signal distortion and harmonics, resistive losses, overheating, starting, and operating power factor. At full load, the Trias SCIG provides a power factor of almost 0.99 . In addition, the machine shows a decrease in losses of approximately $27 \%$ and reduction of 


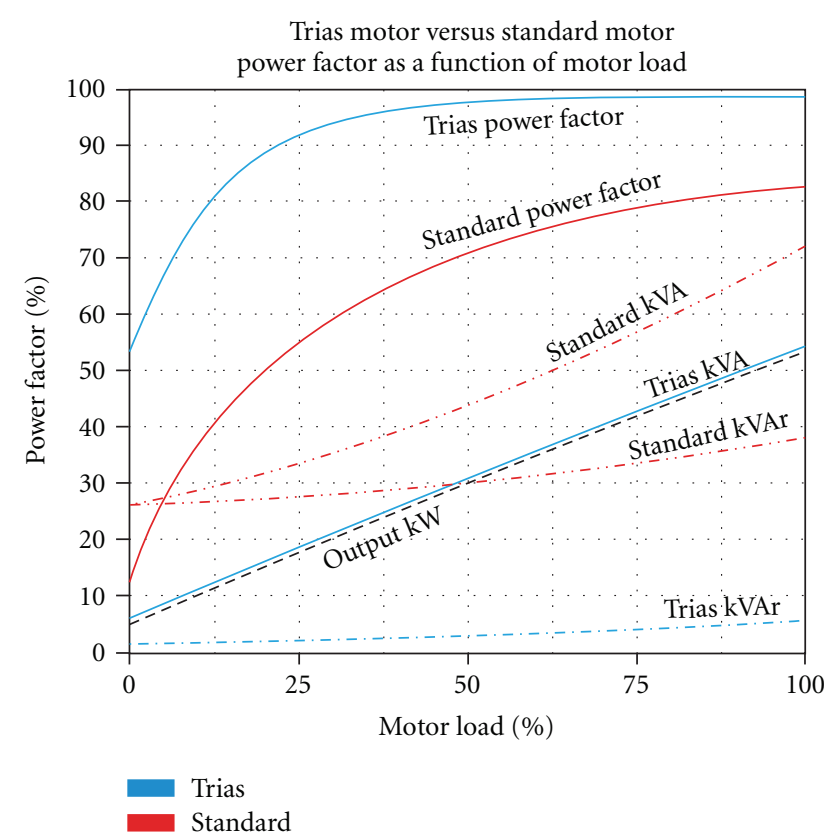

FIGURE 8: Power factor for an induction machine: standard and with auxiliary winding (Trias).

in-rush current, the fact that the machine avoids the problem of overheating.

\section{Discussion and Conclusion}

The performance of an off-the-shelf three-phase induction machine can be enhanced for implementation as a generator in a SWEC to produce electricity to feed grid-connected or off-the-grid loads.

To facilitate the design of such machine, simulation and experimental procedures are presented to predict the steadystate performance of a three-phase induction generator with its stator windings connected under various loading conditions at any power factor. A passive auxiliary winding (LC excitation circuit) connected in wye configuration and magnetically coupled to the main winding of the induction machine has been successfully designed and implemented. The LC-excited induction machine uses capacitance and inductance to match or "tune" the natural occurring impedance in the inductive elements of a machine-allowing the machine to sustain its own magnetic energy internally, virtually independent of the power source. Also, the machine reduces load current up to $30 \%$. Because the utility does not need to supply the magnetization current in the modified induction machine, the full load current is reduced. By reducing peak demand current up to $25 \%$, the net inrush current is reduced. This creates a soft start, extending the life of the machine as well as the life of the SWEC.

The proposed technique involves mathematical modeling and simulation to calculate the values of capacitor and inductor. Experimental results obtained on the laboratory verify the validity of the technique.

\section{Acknowledgments}

The authors are grateful to Ontario Power Authority (OPA), Ontario Centres of Excellence (OCE), and University of Ottawa for their financial support of this project.

\section{References}

[1] E. D. Bassett and F. M. Potter, "Capacitive excitation for induction generators," Electrical Engineering, vol. 35, pp. 540545, 1935.

[2] P. K. Shadhu Khan and J. K. Chatterjee, "Three-phase induction generators: a discussion on performance," Electric Machines and Power Systems, vol. 27, no. 8, pp. 813-832, 1999.

[3] R. C. Bansal, D. P. Kothari, and T. S. Bhatti, "Induction generator for isolated hybrid power system applications: a review," in Proceedings of the 24th National Renewable Energy Convention, pp. 462-467, Bombay, India, December 2000.

[4] C. Grantham, F. Rahman, and D. Seyoum, "A regulated selfexcited induction generator for use in a remote area power supply," International Journal of Renewable Energy, vol. 2, no. 1, pp. 234-239, 2000.

[5] R. C. Bansal, T. S. Bhatti, and D. P. Kothari, "Induction generator for isolated hybrid power system applications: a review," Journal of the Institution of Engineers, vol. 83, pp. 262269, 2003.

[6] B. Singh, R. B. Saxena, S. S. Murthy, and B. P. Singh, "A singlephase induction generator for lighting loads in remote areas," International Journal of Electrical Engineering Education, vol. 25, no. 3, pp. 269-275, 1988.

[7] Y. H. A. Rahim, A. I. Alolah, and R. I. Al-Mudaiheem, "Performance of single phase induction generators," IEEE Transactions on Energy Conversion, vol. 8, no. 3, pp. 389-395, 1993.

[8] O. Ojo and I. Bhat, "Analysis of single-phase self-excited induction generators: model development and steady-state calculations," IEEE Transactions on Energy Conversion, vol. 10, no. 2, pp. 254-260, 1995.

[9] E. Muljadi, T. A. Lipo, and D. W. Novotny, "Power factor enhancement of induction machines by means of solid-state excitation," IEEE Transactions on Power Electronics, vol. 4, no. 4, pp. 409-418, 1989.

[10] T. A. Lettenmaier, D. W. Novotny, and T. A. Lipo, "Singlephase induction motor with an electronically controlled capacitor," IEEE Transactions on Industry Applications, vol. 27, no. 1, pp. 38-43, 1991.

[11] I. Tamrakar and O. P. Malik, "Power factor correction of induction motors using PWM inverter fed auxiliary stator winding," IEEE Transactions on Energy Conversion, vol. 14, no. 3, pp. 426-432, 1999.

[12] C. Suciu, L. Dafinca, M. Kansara, and I. Margineanu, "Switched capacitor fuzzy control for power factor correction in inductive circuits," in Proceedings of the Power Electronics Specialists Conference, Galway, Irlanda, June 2000.

[13] W. Hanguang, C. XIUMIN, L. Xianliang, and Y. Linjuan, "An investigation on three-phase capacitor induction motor," in Proceedings of Third Chinese International Conference on Electrical Machines, pp. 87-90, Xi'an, China, August 1999.

[14] R. C. Bansal, "Three-phase self-excited induction generators: an overview," IEEE Transactions on Energy Conversion, vol. 20, no. 2, pp. 292-299, 2005. 
[15] J. M. Elder, J. T. Boys, and J. L. Woodward, "Self-excited induction machine as low cost generator," IEE Proceedings $C$, vol. 131, no. 2, pp. 33-41, 1984.

[16] S. S. Murthy, "Novel self-excited self-regulated single phase induction generator," IEEE Transactions on Energy Conversion, vol. 8, no. 3, pp. 377-382, 1993.

[17] T. Fukami, Y. Kaburaki, S. Kawahara, and T. Miyamoto, "Performance analysis of a self-regulated self-excited singlephase induction generator using a three-phase machine," IEEE Transactions on Energy Conversion, vol. 14, no. 3, pp. 622-627, 1999.

[18] F. Parasiliti and M. Villani, "Design of high efficiency induction motors with die-casting copper rotors," in Energy Efficiency in Motor Driven Systems, F. Parasiliti and P. Bertoldi, Eds., pp. 144-151, Springer, 2003.

[19] E. F. Brush, J. G. Cowie, D. T. Peters, and D. J. Van Son, "Diecast copper motor rotors: motor test results, copper compared to aluminum," in Energy Efficiency In Motor Driven Systems, F. Parasiliti and P. Bertoldi, Eds., pp. 136-143, Springer, 2003.

[20] R. C. Bansal, T. S. Bhatti, and D. P. Kothari, "Some aspects of grid connected wind electric energy conversion systems," Journal of the Institution of Engineers, vol. 82, pp. 25-28, 2001.

[21] Nordisk Regelsamling (Nordic Grid Code), Nordel, 2004.

[22] T. S. Bhatti, R. C. Bansal, and D. P. Kothari, "Reactive power control of isolated hybrid power systems," in Proceedings of the International Conference on Computer Applications in Electrical Engineering Recent Advances, pp. 626-632, Roorkee, India, February 2002.

[23] B. Singh, S. S. Murthy, and S. Gupta, "Analysis and design of STATCOM-based voltage regulator for self-excited induction generators," IEEE Transactions on Energy Conversion, vol. 19, no. 4, pp. 783-790, 2004.

[24] J. M. Elder, J. T. Boys, and J. L. Woodward, "The process of self excitation in induction generators," IEE Proceedings $B$, vol. 130, no. 2, pp. 103-108, 1983.

[25] S. N. Mahato, M. P. Sharma, and S. P. Singh, "Transient performance of a single-phase self-regulated self-excited induction generator using a three-phase machine," Electric Power Systems Research, vol. 77, no. 7, pp. 839-850, 2007. 

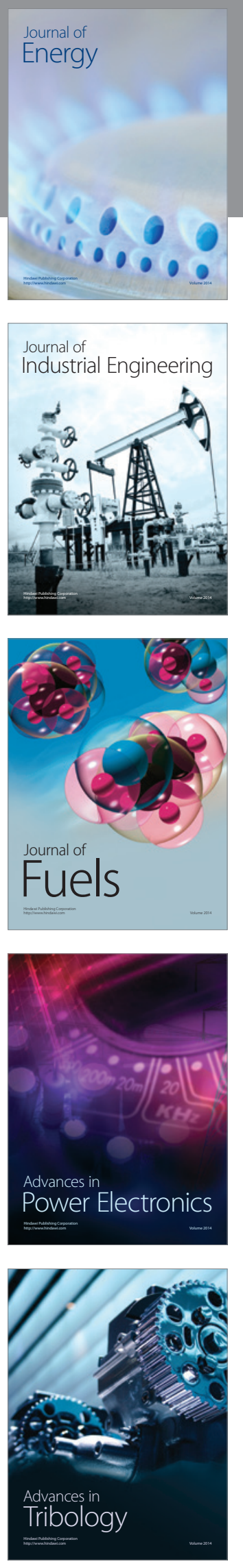
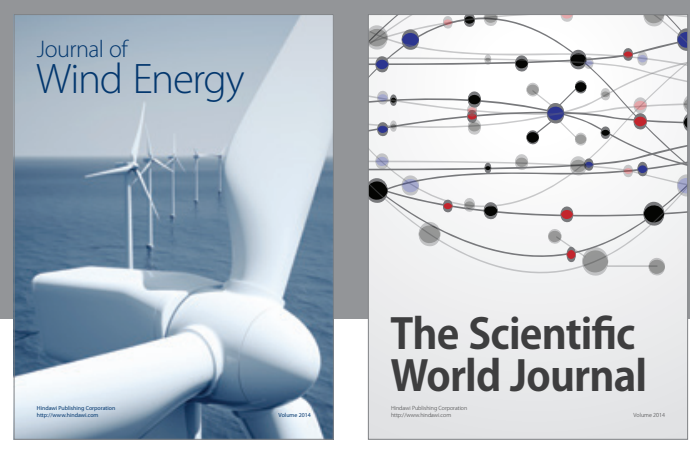

The Scientific World Journal

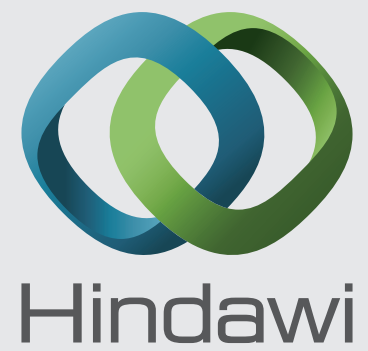

Submit your manuscripts at http://www.hindawi.com
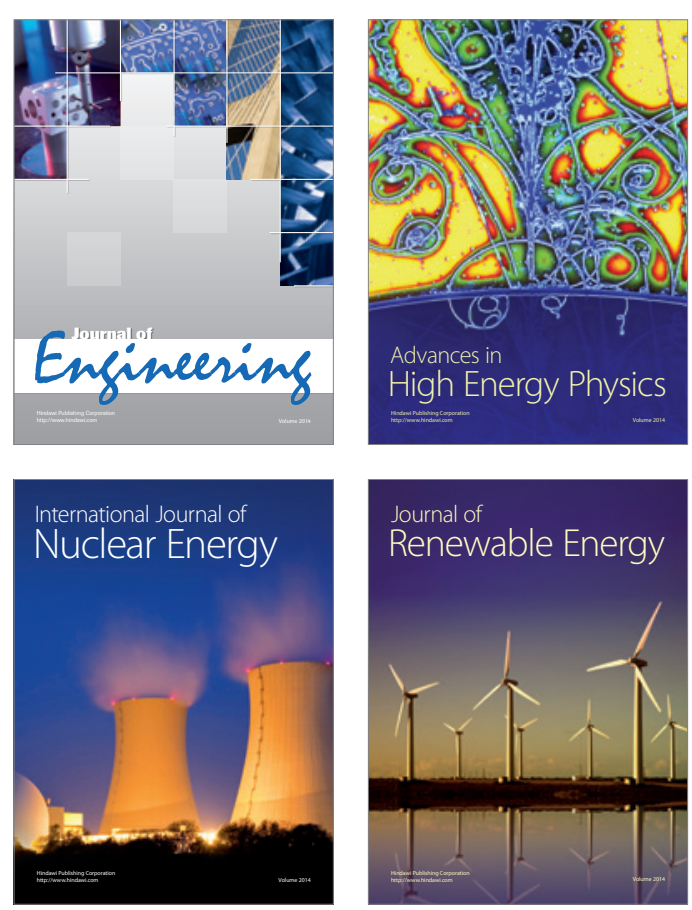

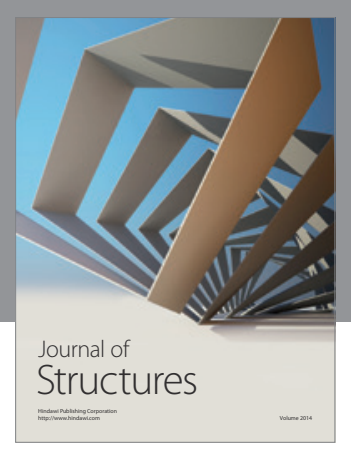

Rotating
Mechinery
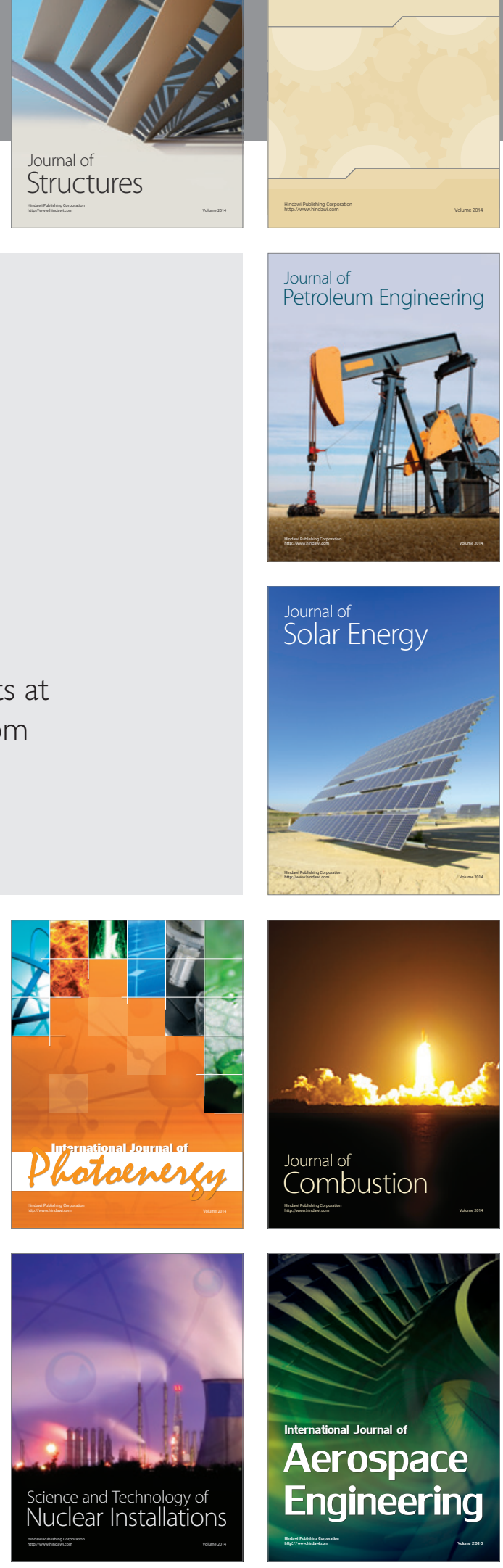